\title{
ESTUDO DA PRODUÇÃO DE ETANOL DE BAGAÇO DE CANA POR COMPLEXO ENZIMÁTICO E Pichia stipitis
}

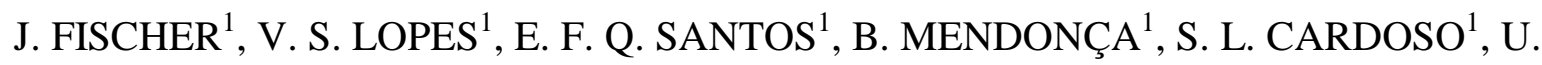 \\ COUTINHO FILHO $^{1}$, V. L. CARDOSO ${ }^{1}$ \\ ${ }^{1}$ Universidade Federal de Uberlândia, Faculdade de Engenharia Química. \\ E-mail para contato: janaffischer@hotmail.com
}

\begin{abstract}
RESUMO- A crescente demanda comercial de etanol alavancou estudos sobre produção de etanol de segunda geração, como forma de reduzir a dependência do petróleo e ampliar a matriz energética brasileira. Neste contexto, se insere o presente trabalho, que estuda a produção de etanol por fermentações alcoólicas de Saccharomyces cerevisiae e Pichia stipitis com de bagaço de cana tratado. A produção de etanol foi realizada por processo de sacarificação e fermentação simultânea em reator batelada com os complexos enzimáticos brutos e $25 \%$ de bagaço de cana-de-açúcar tratado por explosão a vapor, utilizando as leveduras $P$. stipitis e $S$. cerevisiae na forma conjuntas e seqüencial, em diferentes pH, 6,5, 5,5 e 4,5 e tempos de fermentação alcoólica. Os melhores resultados foram obtidos com o uso sequencial de $S$. cerevisiae e P. stipitis: produtividade de 0,30 g/L.h para 48 de fermentação e concentração de etanol de 14,7 g/L com rendimento de $0,294 \mathrm{~g}$ etanol/g celulose para $72 \mathrm{~h}$ de fermentação.
\end{abstract}

\section{INTRODUÇÃO}

O esgotamento dos combustíveis fósseis incentiva a busca por fontes de energia renovável, como o etanol com base em matérias-primas ricas em carboidratos complexos, incluindo amido, oligossacarídeos e biomassa celulósica. Geralmente, o etanol produzido a partir de carboidratos complexos segue quatro etapas de processo: pré-tratamento da biomassa para abertura das fibras, hidrólise enzimática para obtenção de açúcares fermentescíveis, fermentação destes açúcares em etanol, separação e purificação (Binod et al., 2012, Rocha et al., 2013).

Em processos de produção de bioetanol celulósico, o aproveitamento de resíduos agroindustriais deve ser visto como um processo integrado, com utilização da lignina, assim como a fermentação dos açúcares, hexoses e pentoses, presentes na biomassa de celulose. Neste contexto, o uso de microorganismos capazes de fermentar as pentoses representa uma necessidade para pleno aproveitamento 


\section{9 a 22 de outubro de 2014 \\ Florianópolis/SC}

da biomassa. Entre todos os micro-organismos capazes de fermentar pentoses (xilose e arabinose), a levedura Pichia stipitis se destaca pela sua capacidade natural de realizar estas fermentações e produzir diretamente etanol (Lin et al., 2012; Agboggo, Coward-Kelly, 2008).

As pentoses são geradas tanto no pré-tratamento de biomassas ricas em celulose, como no processo de hidrólise enzimática necessário para liberação de glicose da biomassa, de forma a favorecer a fermentação tradicional da glicose, por Saccharomyces cerevisiae. As fermentações alcoólicas podem ser realizadas de forma conjunta com a Pichia, visando conjugar o melhor crescimento e produção de etanol de $S$. cerevisiae a facilidade de fermentação de pentose em metabolismo diáuxico que só favorece a fermentação de pentoses ao fím da conversão de hexoses (Lin et al., 2012; Grootjen et al., 1990).

Entre as diferentes investigações de uso conjunto de Saccharomyces e Pichia tem-se o interesse de redução do custo de uso de celulases, que hoje é o principal obstáculo à utilização de biomassa celulósica. Neste contexto, o objetivo deste avaliar a utilização de Pichia stipitis e Saccharomyces cerevisiae na fermentação de alcoólica simultânea e ampliar os estudos do uso de complexos enzimáticos brutos produzidos por fermentação em estado sólido (FES) de resíduos agroindustriais na hidrólise enzimática dos materiais lignocelulósicos.

\section{MATERIAL E MÉTODOS}

\subsection{Micro-organismos e biomassas}

Foi utilizado Aspergillus niger (I5), selecionado entre 66 culturas de fungos coletados do Cerrado do Triângulo Mineiro (Uberlândia/MG) (Fischer et al., 2013). A levedura utilizada nas fermentações alcoólicas foi a cepa Saccharomyces cerevisiae Y904, produzida pela Mauri Brasil Ind. Com. Ltda, na forma liofilizada e também foi utilizada Pichia Stipitis (ATCC 58376). As biomassas utilizadas foram: farelo do beneficiamento de arroz, obtido de uma beneficiadora da região, e bagaço de cana-de-açúcar, pré-tratado com explosão a vapor na condição de baixa severidade $\left(12 \mathrm{kgf} / \mathrm{cm}^{2}, 8\right.$ min.), gentilmente cedido pelo CTC (Centro de Tecnologia Canavieira) de Piracicaba/SP. Todos os micro-organismos e biomassas foram estocados sob refrigeração $\left(5 \pm 1^{\circ} \mathrm{C}\right)$.

\subsection{Fermentações}

Fermentação em estado sólido (FES): As FES destinadas à produção de complexo enzimático bruto foram realizadas em reator estático, contendo $10^{7}$ a $10^{8}$ células/g de Aspergillus niger e substrato sólido, sendo $60 \%$ de farelo do beneficiamento de arroz e $40 \%$ de bagaço de cana-de-açúcar tratado (composição média em base seca, \%: celulose 62,4, hemicelulose 15,1 e lignina 23,2 Fischer, 2014). O tempo de fermentação foi de $72 \mathrm{~h}$ e a temperatura de $30 \pm 1^{\circ} \mathrm{C}$. Os complexos enzimáticos foram extraídos com solução de Tween 80 (1\%) em água (Fischer et al.,2013).

Fermentação alcoólica: a produção de etanol foi realizada com complexo enzimático bruto, com sacarificação e fermentação simultâneas de bagaço de cana tratado, em reator batelada de $250 \mathrm{~mL}$ com volume reacional de $100 \mathrm{~mL}$ (25 g de bagaço para $100 \mathrm{~mL}$ de extrato enzimático), sobre mesa 


\section{9 a 22 de outubro de 2014 \\ Florianópolis/SC}

agitada a $150 \mathrm{rpm}, 30 \pm 1^{\circ} \mathrm{C}$. As leveduras Pichia stipitis e Saccharomyces cerevisiae foram utilizadas nas concentrações iniciais de inóculo de $10^{8}$ células $/ \mathrm{mL}$ e $30 \mathrm{~g} / \mathrm{L}$, respectivamente, em cinco condições distintas descritas na Tabela 1.

Tabela 1 - Condições de fermentação alcoólica conjunta por P. stipitis e $S$. cerevisiae com diferentes formas de adição de micro-organismo e correção de $\mathrm{pH}^{*}$

\begin{tabular}{|c|c|}
\hline Experimento & Descrição \\
\hline A & $\begin{array}{l}\text { Inóculo com células de } P \text {. stipitis e } S \text {. cerevisiae foi adicionado no início da } \\
\text { fermentação e o pH inicial de fermentação de } 6,5 \text {. }\end{array}$ \\
\hline B & pH de fermentação de 5,5 e demais condições idênticas das descritas no experimentos \\
\hline $\mathrm{C}$ & pH de fermentação de 4,5 e demais condições idênticas das descritas no experimentos \\
\hline $\mathrm{D}$ & $\begin{array}{l}\text { Início da fermentação com inóculo de } S \text {. cerevisiae em } \mathrm{pH} 4,5 \text {, seguido pela adição } \\
\text { de um segundo inóculo de } P \text {. stipitis após } 24 \text { h de fermentação, sendo que o pH no } \\
\text { momento de adição de segundo inóculo foi corrido para } 6,5 \text {. }\end{array}$ \\
\hline $\mathrm{E}$ & $\begin{array}{l}\text { Início da fermentação com inóculo de } P \text {. stipitis em pH 6,5, seguido pela adição de } \\
\text { um segundo inóculo de } S \text {. cerevisiae após } 48 \text { h de fermentação com correção do pH no } \\
\text { momento de adição de segundo inóculo para 4,5. }\end{array}$ \\
\hline
\end{tabular}

*Nota: ajuste do pH do meio feita pela adição de $\mathrm{HCl} 0,1 \mathrm{M}$ e $\mathrm{NaOH} 0,1 \mathrm{M}$.

\subsection{Métodos analíticos}

A concentração de etanol, pentoses e hexoses foi determinada por cromatografia líquida (Shimadzu model LC-20A Prominence, coluna Ca Supelcogel), a solução de arraste utilizada foi água deionizada, a vazão de $0,5 \mathrm{~mL} / \mathrm{min}$, temperatura do forno de $80^{\circ} \mathrm{C}$ e volume de injeção de $20 \mu \mathrm{L}$. A atividade da celulase total (FPase) foi determinada pela hidrólise de papel de filtro Whatman $\mathrm{n}^{\circ} 1$. Para determinação da atividade das exoglucanases utilizou-se solução de celulose cristalina (Avicel) como substrato. A atividade da endocelulase foi determinada pela hidrólise de carboximetilcelulose (CMC) e a atividade de $\beta$-glicosidase (celobiase) determinada pela hidrólise de celobiose (Ghose, 1987; Adriano, 2008).

\section{RESULTADOS E DISCUSSÃO}

A avaliação dos extratos enzimáticos brutos produzidos mostrou que o mesmo apresentou atividade em FPase de 1,51 (UFP/mL), $\beta$-glicosidade 1,05 (U $\left.\mathrm{U}_{\text {Celobiose }} / \mathrm{mL}\right)$, exoglucanase 0,23 $\left(\mathrm{U}_{\text {avicel }} / \mathrm{mL}\right)$ e endoglucanase $1,33\left(\mathrm{U}_{\mathrm{CMC}} / \mathrm{mL}\right)$, demonstrando que o mesmo tem potencial para degradação da celulose.

Na Tabela 2 são apresentados os resultados da fermentação de $P$. stipitis e $S$. cerevisiae, em $\mathrm{pH}$ 6,5 , pode se observar que a $P$. stipitis tem a capacidade de fermentar pentoses e hexoses e o tempo de $24 \mathrm{~h}$ é adequado para o processo, pois para $48 \mathrm{~h}$ não houve aumento na concentração de etanol. $\mathrm{O}$ valor da concentração de etanol de 10,8 g/L obtido após 24 h sugere que o uso de hidrólise simultânea 
a fermentação é uma proposta promissora, pois os resultados de etanol obtidos nesta configuração podem ser melhorados, tanto pelo uso de estratégias distintas de alimentação de bagaço durante a fermentação, como pelo uso de aditivos, a exemplo da lacase e líquidos iônicos (Li et al., 2014; Lever et al., 2010).

Tabela 2 - Concentrações dos diferentes constituintes de meio para diferentes tempos de fermentação alcoólica e pH 6,5 - Teste A

\begin{tabular}{|c|c|c|}
\hline & P. stipitis + S. cerevisiae 24 h & P. stipitis + S. cerevisiae 48 h \\
\hline Glicose (g/L) & - & - \\
\hline Celobiose (g/L) & - & - \\
\hline Xilose (g/L) & 5,79 & 1,05 \\
\hline Manose (g/L) & 2,65 & 2,20 \\
\hline Arabinose (g/L) & 2,58 & 2,83 \\
\hline Glicerol (g/L) & - & 0,80 \\
\hline Etanol (g/L) & 10,8 & 10,8 \\
\hline
\end{tabular}

Também pode ser observado na Tabela 2, que uso dos micro-organismos conjuntamente, no pH testado, deve ser reavaliado em outras condições de $\mathrm{pH}$ ou ainda de adição de micro-organismos em diferentes etapas de fermentação, pois a concentração de etanol $(10,8 \mathrm{~g} / \mathrm{L})$ esteja próxima da citada na literatura por diversos pesquisadores para utilização de $S$. cerevisiae (SUKUMARAN et al., 2009; LEVER et al., 2010; ROCHA et al., 2013). Há a possibilidade de comportamento diáuxico da $P$. stipitis, competindo com a $S$. cerevisiae, que faz com que na abundância de glicose ela venha à só utilizar pentoses ao esgotamento da glicose (GROOTJEN, 1991; LIN et al., 2012).

Nas Tabelas 3 e 4 são apresentados os resultados da fermentação conjunta de $P$. stipitis e $S$. cerevisiae em condições dos experimentos B e C (Tabela 1). Pode-se observar que a redução do $\mathrm{pH}$ favorece o crescimento da Saccharomyces e consequentemente a produção de maior quantidade de etanol. Este fato deve-se ao $\mathrm{pH}$ próximo a 4,5 ser valor usual nas fermentações com esta levedura.

Tabela 3 - Concentrações dos diferentes constituintes de meio para diferentes tempos de fermentação alcoólica pH 5,5 - Teste B

\begin{tabular}{|c|c|c|}
\hline Componentes & P. stipitis + S. cerevisiae 24 h & P. stipitis + S. cerevisiae 48 h \\
\hline Glicose (g/L) & - & - \\
\hline Celobiose (g/L) & - & 2,67 \\
\hline Xilose (g/L) & 4,26 & 3,98 \\
\hline Manose (g/L) & 2,38 & 2,44 \\
\hline Arabinose (g/L) & 3,65 & 2,32 \\
\hline Glicerol (g/L) & 1,06 & 0,79 \\
\hline Etanol (g/L) & 8,38 & 7,9 \\
\hline
\end{tabular}


Tabela 4 - Concentrações dos diferentes constituintes de meio para diferentes tempos de fermentação alcoólica pH 4,5 - Teste C

\begin{tabular}{|c|c|c|}
\hline Componentes & P. stipitis + S. cerevisiae 24 h & P. stipitis + S. cerevisiae $\mathbf{4 8 ~ h}$ \\
\hline Glicose $(\mathrm{g} / \mathrm{L})$ & - & - \\
\hline Celobiose $(\mathrm{g} / \mathrm{L})$ & - & - \\
\hline Xilose $(\mathrm{g} / \mathrm{L})$ & 5,49 & 5,92 \\
\hline Manose $(\mathrm{g} / \mathrm{L})$ & 2,52 & 2,30 \\
\hline Arabinose $(\mathrm{g} / \mathrm{L})$ & 2,43 & 2,60 \\
\hline Glicerol $(\mathrm{g} / \mathrm{L})$ & 1,22 & 1,18 \\
\hline Etanol $(\mathrm{g} / \mathrm{L})$ & 10,2 & 10,1 \\
\hline
\end{tabular}

A comparação entre os melhores resultados dos experimentos A, B e C (Tabela 2 a 4) mostram que na fermentação com adição simultânea dos micro-organismos, os valores de pHs de 4,5 e 6,5 foram mais adequados, e por esta razão, estes pHs foram usados nos experimentos D e E.

Nas Tabelas 5 e 6 são apresentados os resultados da concentração de etanol para o uso de sequencial da adição de $S$. cerevisiae e $P$. stipitis, com adição inicial de $P$. stipitis em $24 \mathrm{~h}$ de processo (Tabela 5) e com adição inicial de $P$. stipitis seguida de $S$. cerevisiae após 48 h (Tabela 6). Pode-se observar que a fermentação nestas sequências favorece a maior produção de etanol, pois reduz o metabolismo diáuxico que leva a Pichia a consumir primeiro a glicose. Outro fato que pode ser observado é a que fermentação com a $P$. stipitis é mais favorecida para $\mathrm{pH}$ de 6,5 comparado com $\mathrm{pH} 4,5$.

A comparação entre os resultados das Tabelas 5 e 6 (adição sequencial de micro-organismos) com os resultados de adição simultânea (Tabelas 2, 3 e 4), mostra que a adição sequencial dos microrganismos representam a estratégia de cofermentação mais favorável, sendo que no uso sequencial de $S$. cerevisiae e $P$. stipitis a produtividade de $0,30 \mathrm{~g} / \mathrm{L}$.h para $48 \mathrm{~h}$ de fermentação a concentração de etanol foi de $14,7 \mathrm{~g} / \mathrm{L}$ com rendimento de $0,294 \mathrm{~g}$ etanol/g celulose para $72 \mathrm{~h}$ de fermentação, este resultado favorece 1,11 vezes mais etanol do que o processo sequencial de $P$. stipitis e S. cerevisiae.

Tabela 5 - Concentrações dos diferentes constituintes de meio para diferentes tempos de fermentação alcoólica - Teste D

\begin{tabular}{|c|c|c|c|c|}
\hline Componentes & S. cerevisiae 24 h & P. stipitis 24 h & P. stipitis 48 h & P. stipitis 72 h \\
\hline Xilose $(\mathrm{g} / \mathrm{L})$ & 3,82 & 1,68 & 0,18 & - \\
\hline Manose $(\mathrm{g} / \mathrm{L})$ & 2,31 & 2,91 & 2,42 & 0,37 \\
\hline Arabinose $(\mathrm{g} / \mathrm{L})$ & 2,15 & 0,71 & 1,08 & 0,91 \\
\hline Glicerol $(\mathrm{g} / \mathrm{L})$ & 1,32 & 1,30 & 1,11 & 0,47 \\
\hline Etanol $(\mathrm{g} / \mathrm{L})$ & 12,8 & 14,4 & 14,7 & 14,2 \\
\hline
\end{tabular}


Tabela 6 - Concentrações dos diferentes constituintes de meio para diferentes tempos de fermentação alcoólica - Teste E

\begin{tabular}{|l|c|c|c|c|}
\hline Componentes & P. stipitis 24 h & P. stipitis 48 h & S. cerevisiae 24 h & S. cerevisiae 48 h \\
\hline Xilose $(\mathrm{g} / \mathrm{L})$ & 3,31 & 0,93 & - & - \\
\hline Manose $(\mathrm{g} / \mathrm{L})$ & 2,23 & 1,47 & 0,82 & 0,82 \\
\hline Arabinose $(\mathrm{g} / \mathrm{L})$ & 2,00 & 0,15 & 0,14 & 0,30 \\
\hline Glicerol $(\mathrm{g} / \mathrm{L})$ & 1,29 & 1,23 & 0,98 & 0,40 \\
\hline Etanol $(\mathrm{g} / \mathrm{L})$ & 11,9 & 13,7 & 13,3 & 13,1 \\
\hline
\end{tabular}

\section{CONCLUSÃO}

A comparação entre uso de fermentações sequênciais de $S$. cerevisiae e $P$. stipitis e fermentações sequências de $P$. stipitis e $S$. cerevisiae mostram que a primeira situação favorece mais a produção de etanol sendo que o $\mathrm{pH}$ 4,5 foi o mais favorável para $S$. cerevisiae e $\mathrm{pH} 6,5$ para $P$. stipitis. Estes resultados mostram caminhos promissores na produção de etanol de resíduos lignocelulósicos e extratos enzimáticos brutos.

\section{AGRADECIMENTOS}

Os autores agradecem ao CNPq (Projeto 550940/2010-3, Edital 046/2009), FAPEMIG (Processo PCE-00089-14) e UFU pelo apoio financeiro e ao Centro de Cultura Canavieira (CTC) pela parceria em estudos conjuntos relacionados à produção de etanol.

\section{REFERENCIAS}

AGBOGGO, F.K.; COWARD-KELLY, G. Cellulosic ethanol production using the naturally occurring xylose-fermenting yeast, Pichia stipitis. Biotechnol Lett., v. 30, n.9, p.1515-1524, 2008.

ADRIANO, W. S. Preparação e Caracterização de Derivados de Enzimas Industriais em Quitosana. 2008. Tese (Doutorado em Engenharia Química) - Universidade Federal de São Carlos, São Carlos, SP.

BINOD, P.; KUTTIRAJA, M.; ARCHANA, M.; USHA, J.K.; SINDHU, R.; SUKUMARAN R.K.; PANDEY, A. High temperature pretreatment and hydrolysis of cotton stalk for producing sugars for bioethanol production, Fuel, v. 92, p. 340-345, 2012.

FISCHER, J. Produção de etanol de segunda geração pelo uso de complexo enzimático de cepas selecionadas do ecossistema do Cerrado, 2014. Tese (Doutorado em Engenharia Química) Universidade Federal de Uberlândia. Faculdade de Engenharia Química, Uberlândia, MG.

FISCHER, J.; LOPES, V.; GALVÃO, C.; TEODORO, J.; FILHO, U.; CARDOSO, V. Utilization of Cheese Whey and Cellulosic Biomass for Production of Ethanol by Selected Fungi Strain from Brazilian Savannas. Chem. Eng. Trans., v. 32, p. 1075-1080, 2013. 
GHOSE, T. K. Measurement of Cellulase Activities. Pure and Applied Chemistry, v. 59, n. 2, p. 257268, 1987.

GROOTJEN, D.R.J.; MEIJLIK, H.H.M.; LANS, R.G.K.M.; LUBEN, A.M. Cofermetation of glucose and xylose with immobilized Pichia stipitis and Saccharomyces cerevisiae. Enzyme Microb. Technol., v.12, p. 859-864, 1990.

LEVER, M.; HO, G.; CORD-RUWISCH, R. Ethanol from lignocellulose using crude unprocessed cellulose from solid-state fermentation. Bioresour. Technol., v. 101, n. 18, p. 7083-7087, 2010.

LI, J.; LIN, J.; ZHOU, P.; WU, K.; LIU, H.; XIONG, C.; GONG. Y.; XIAO, W.; LIU, Z. One-pot simultaneous saccharification and fermentation: a preliminary study of a novel configuration for cellulosic ethanol production. Bioresour. Technol., v. 161, p. 171-178, 2014.

LIN, T.H.; HUANG, C.F.; GUO, G.L.; HWANG, W.S.; HUANG, S.L. Pilot-scale ethanol production from rice straw hydrolysates using xylose-fermenting Pichia stipitis. Bioresour. Technol., v.116, p. 314-319, 2012.

ROCHA, N.R.A.F.; BARROS, M.A.; FISCHER, J.; FILHO, U.C.; CARDOSO, V. L. Ethanol production from agroindustrial biomass using a crude enzyme complex produced by Aspergillus niger. Renewable Energy, v. 57, p. 432-435, 2013.

SUKUMARAN, R., K.; SINGHANIA, R. R.; MATHEW, G. M.; PANDEY, A. Cellulase production using biomass feed stock an its application in lignocelluloses saccharification for bio-ethanol production. Renewable Energy, n. 34, p. 421-424, 2009. 